\title{
ANALISIS KEPUASAN KONSUMEN PADA PEMBELIAN PRODUK DI ADITI COFFEE HOUSE AND SPACE
}

\section{ANALYSIS OF CUSTOMER SATISFACTION ON PRODUCT PURCHASES AT ADITI COFFEE HOUSE AND SPACE}

\author{
Rizki Darmawan Karmana*, Dini Rochdiani \\ Universitas Padjadjatan, Jl. Raya Sumedang-Bandung, Jawa Barat 45363 \\ *Email: rizkidkarmana@gmail.com
}

(Diterima 30-03-2020; Disetujui 12-05-2020)

\begin{abstract}
ABSTRAK
Produksi kopi di Indonesia pada tahun 2017 mencapai 668,88 ribu ton. Tingkat kebutuhan kopi di Indonesia terus meningkat dalam kurun waktu lima tahun terakhir, artinya tingkat konsumsi kopi di Indonesia terus meningkat. Meningkatnya konsumsi kopi di Indonesia dimanfaatkan oleh para pelaku bisnis untuk membuka kedai kopi. Kedai kopi sudah menjadi trend atau gaya hidup masyarakat, khususnya di Kota Bandung. Pada tahun 2017 sampai 2019, tercatat ada 85 kedai kopi yang tersebar di setiap sudut Kota Bandung. Maraknya kehadiran kedai kopi membuat konsumen memiliki pilihan atau opsi kedai kopi mana yang akan dikunjungi. Kepuasan konsumen menjadi salah satu faktor penting untuk memikat konsumen agar selalu menjadi pilihan utama. Kepuasan konsumen adalah ungkapan perasaan pelanggan yang muncul dari hasil evaluasi setelah membandingkan apa yang didapatkan dengan apa yang diharapkan. Aditi Coffee House and Space adalah salah satu kedai kopi yang memiliki masalah dalam mengenal karakteristik dan penilaian konsumen sebagai bahan evaluasi agar dapat terus bersaing ditengah maraknya kehadiran kedai kopi di Kota Bandung. Desain pada penelitian ini menggunakan desain kualitatif dengan analisis deskriptif dibantu dengan alat analisis kepuasan pelanggan menggunakan metode Customer Satisfaction Index (CSI). Angka indeks kepuasan pelanggan menunjukan angkat 93,25\% yang artinya sangat puas.
\end{abstract}

Kata kunci: Kopi, Kedai Kopi, Konsumen, Kepuasan, CSI

\begin{abstract}
Indonesia coffee production in 2017 reached 668,88 thousand tons. The level of coffee demand in Indonesia has continued to increase in the last five years. This means that the level of coffee consumption in Indonesia continues to increase. The increasing consumption of coffee in Indonesia is used by businesses to open coffee shops. Coffee shops have become a trend or lifestyle, especially in the city of Bandung. In 2017-2019, there were 85 coffee shops scattered in every corner of the city of Bandung. The rise of the presence of coffee shops make consumers have a choice or option which coffee shop to visit. Consumer satisfaction is one important factor to lure consumers to always be the first choice. Consumer satisfaction is an expression of customer feelings that arise from the results of an evaluation after comparing what is obtained with what is expected. Aditi Coffee House and Space is one of the coffee shops that has problems in identifying the characteristics and ratings of consumers as an evaluation material in order to continue to compete amid the growing presence of coffee shops in the city of Bandung. The design in this study used a qualitative design with descriptive analysis assisted with customer satisfaction analysis tools using the Customer Satisfaction Index (CSI) method. Consumer satisfaction index figures show lift $93.25 \%$ which means very satisfied.
\end{abstract}

Keywords: Coffee, Coffee Shop, Consumer, Satisfaction, CSI 


\section{PENDAHULUAN}

Produksi kopi di Indonesia pada tahun 2017 mencapai 668,68 ribu ton. Jumlah tersebut berasal dari 1,25 juta hektar luas area perkebunan kopi, sebanyak $95,37 \%$ dikelola oleh perkebunan milik rakyat (PR) sedangkan sisanya dikelola oleh perkebunan besar milik swasta (PBS) sebesar 2,48\% dan perkebunan besar milik negara $(\mathrm{PBN})$ sebesar 2,25\%. (Outlook Komoditas Pertanian Subsektor Perkebunan Kopi, 2018).

Sebagai salah satu produsen kopi terbesar di dunia, tingkat kebutuhan kopi di Indonesia terus meningkat dalam kurun waktu lima tahun terakhir. Artinya, tingkat konsumsi kopi di Indonesia terus meningkat sebagai mana di tunjukan oleh Gambar 1.

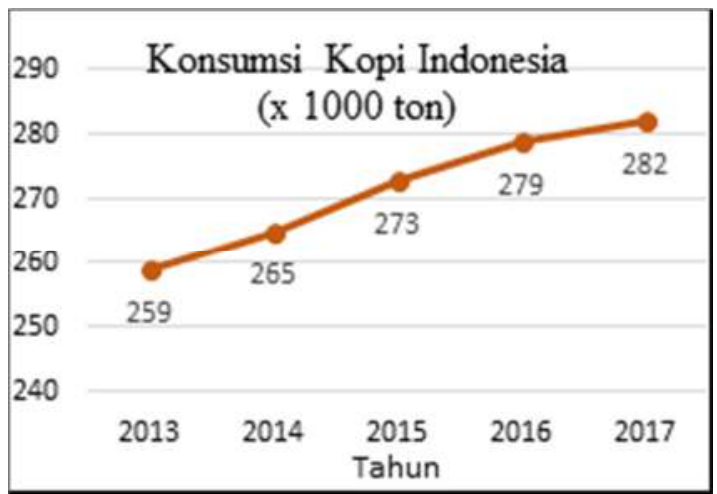

Gambar 1. Konsumsi Kopi di Indonesia

Sumber: International Coffee Organizations (2018).

Seiring dengan peningkatan konsumsi kopi mengindikasikan bahwa masyarakat Indonesia sangat gemar mengonsumsi kopi, baik dari segi rasa yang dipengaruhi oleh cara pengolahan maupun suasana yang ditawarkan oleh kedai kopi yang dinilai sudah menjadi trend masa kini. Menurut Hoffman (2014), setelah muncul ilmu dan teknik pembuatan kopi, olahan kopi semakin memiliki citarasa khas dan menarik sehingga menjadi daya tarik tersendiri bagi konsumen.

Kedai kopi merupakan tempat yang menyediakan berbagai jenis kopi, dan minuman non-alkohol lainnya dalam suasana santai, tempat nyaman, dan dilengkapi dengan alunan musik, baik lewat pemutar atau pun live music, menyediakan televisi dan bacaan, desain interior khas, pelayanan yang ramah, dan beberapa diantaranya menyediakan koneksi internet nirkabel (Herlyana, 2012). Seiring dengan meningkatnya konsumsi kopi di Indonesia, semakin banyak pula masyarakat yang mengambil kesempatan untuk membuka kedai kopi khususnya di kota Bandung. Pada tahun 2015 terdapat 94 kedai kopi yang terdaftar di Bandung, sedangkan pada akhir tahun 2018 terdapat 126 kedai kopi yang terdaftar (Manual Brew Community, 2018). Berikut adalah daftar kedai kopi di Kota Bandung pada tahun 2017 hingga 
2019 dapat dilihat pada Tabel 1. hingga

Tabel 3.

Tabel 1. Daftar Kedai Kopi di Bandung Tahun 2017

\begin{tabular}{|c|c|c|}
\hline No & Nama Kedai kopi & Lokasi \\
\hline 1. & Mimiti Coffee & Jl. Sumur Bandung No. 14 \\
\hline 2. & Call Me Bro & J1. Lengkong Besar No. 6-8 \\
\hline 3. & Kiputih Satu & Jl. Kiputih 1A, Ciumbuleuit \\
\hline 4. & Armor Leuit & Jl. Bukit Pakar Utara No. 10 \\
\hline 5. & Daily Breu & Jl. Rontgen No. 9 \\
\hline 6. & Eiger Coffee Cihampelas & Jl. Cihampelas No. 22 \\
\hline 7. & Grind Joe & Jl. Dago No. 69 \\
\hline 8. & Budaraa & Jl. Bukit Dago Utara II No. 11 \\
\hline 9. & Roempi & J1. Anggrek No. 27 \\
\hline 10. & Kopi Barli & Jl. Professor Doktor Sutami No. 91 \\
\hline 11. & Cupola & Jl. Lapang Supratman No. 4 \\
\hline 12. & Ambrogio Pattiserie & Jl. Banda No. 26 \\
\hline 13. & Next 8 Coffee and Food & Jl. Cendana No. 8 \\
\hline 14. & Boyle's Coffee & Komplek Surya Setra Blok C No. 2 \\
\hline 15. & Lula Bakery \& Coffee & Jl. Citarum No. 12 \\
\hline 16. & Woodlane & Jl. Anggrek No. 36 \\
\hline 17. & Pillow Talk Coffee \& Comfy & Jl. Haji Hasan No. 12 \\
\hline 18. & Yumaju Coffee & Jl. Maulana Yusuf No. 10 \\
\hline 19. & Abraham and Smith & Jl. Gudang Selatan No. 22 (Gedung A) \\
\hline 20. & Barleu Coffeeshop & Jl. Anggrek No. 55 \\
\hline 21. & Ruckerpark Coffee Culture & J1. Dr Cipto No. 24 \\
\hline 22. & Aditi Coffee House and Space & Jl. K.H Ahmad Dahlan No. 5 \\
\hline 23. & Kamar Tujuh Coffee & Jl. Cilamaya No. 1 \\
\hline 24. & Sejiwa Coffee & Jl. Progo No. 15 \\
\hline 25. & Contrast Coffee & Jl. Anggrek No. 6 \\
\hline 26. & General.co & Paskal Hypersquare \\
\hline
\end{tabular}

Sumber: Daftar Kedai Kopi Baru di Kota Bandung 2017

Tabel 2. Daftar Kedai Kopi di Kota Bandung Tahun 2018

\begin{tabular}{|c|c|c|}
\hline No & Nama Kedai kopi & Lokasi \\
\hline 1. & Lalune Coffee \& Luncheonette & Jl. Hegarmanah No. 12 \\
\hline 2. & Kudu Ngopi & J1. Aceh 66B \\
\hline 3. & Warung Kopi Limarasa & Jl. Braga No. 36 \\
\hline 4. & Buih Kopi & J1. Trunojoyo No. 40 \\
\hline 5. & Carla Living & Ground Floor, Festival Citylink \\
\hline 6. & The Potting Shed & Jl. Panumbang Jaya No. 5 \\
\hline 7. & Masagi Koffee & J1. Gunung Kareumbi 1B \\
\hline 8. & Hi, Brew! Coffee & Jl. Boscha No. 43 \\
\hline 9. & Wheels Coffee Roaster & J1. Prof Eyckman No. 32 \\
\hline 10. & Antico Coffee & Jl. Cilaki No. 9 \\
\hline 11. & Kopi Toko Djawa & Jl. Braga No. 79 \\
\hline 12. & Wake Cup Coffee & Jl. Kebon Kawung No. 16 \\
\hline 13. & Kopitera & Jl. Burangrang No. 14 \\
\hline 14. & Dreezel Coffee & Jl. Cisangkuy No. 56 \\
\hline 15. & Cozy Cube & Jl. Taman Cibeunying Utara No. 4 \\
\hline 16. & Kopi Atim & Jl. Gang Atim No. 1 \\
\hline 17. & Hara & J1. Professor Soetami No. 62 \\
\hline 18. & The Soko & Jl. Raya Resort Dago Pakar No. 19 \\
\hline 19. & Akasya Teras & Jl. Resort Dago Pakar No. 18 \\
\hline
\end{tabular}




\begin{tabular}{lll}
\hline No & \multicolumn{1}{c}{ Nama Kedai kopi } & \multicolumn{1}{c}{ Lokasi } \\
\hline 20. & Mr Guan Coffee \& Books & Jl. Tampomas No. 22 \\
21. & Spadaa Koffie & Jl. Ternate No. 5 \\
22. & Toby's Estate & Lobby Cai, 23 Paskal \\
23. & Wheeler's Coffee & Jl. Veteran No. 21 \\
24. & Kuro Koffee & Jl. Sukaasih 1 \\
25. & Diskus Café \& Bites & Jl. Terusan Babakan Jeruk 1 No. 109 \\
26. & Kedai Juru & Jl. Ambon No. 9 \\
27. & Sensys & Jl. Ambon No. 19 \\
28. & Goutte Coffee \& Tea & Jl. Wira Angun-Angun \\
29. & Black Ground Café \& Eatery & Jl. Banceuy No. 3 \\
30. & U\&KL Tea \& Coffee & Jl. Trunojoyo No. 4 \\
31. & Marka Coffee & Jl. Talaga Bodas No. 32 \\
32. & 9/1/1 Coffee Lab & Jl. Halmamera No. 2 \\
33. & U Coffee & Jl. Lombok No. 10 \\
34. & Lazy Lolla & Jl. Anggrek No. 29 \\
35. & Please Please Please & Jl. Progo No. 37 \\
\hline
\end{tabular}

Tabel 3. Daftar Kedai Kopi di Kota Bandung Tahun 2019

\begin{tabular}{|c|c|c|}
\hline No & Nama Kedai kopi & Lokasi \\
\hline 1. & Teman Lama & Jl. Bima No. 80 \\
\hline 2. & Kopi Alit & Gang Nyi Empok No. 19 \\
\hline 3. & Work Coffee & Jl. Sumbawa No. 28 \\
\hline 4. & Yumaju 2.0 & Jl. Menado \\
\hline 5. & Kurokoffee & Jl. Ciumbuleuit No. 130 \\
\hline 6. & Sudut Kopi & Jl. Pandawa No. 2 \\
\hline 7. & Coffeelensebrew & Jl. Panaitan No. 22 \\
\hline 8. & Serantau Coffee & Jl. Lombok No. 19 \\
\hline 9. & Kopi Koma & Jl. Siliwangi No. 8 \\
\hline 10. & Musat & Jl. Cilaki No. 45 \\
\hline 11. & Kopi Sajati & Jl. Raya Kopo No. 200 \\
\hline 12. & Contou Coffee & Jl. Taman Cempaka No. 6 \\
\hline 13. & Gajua Kopi & Jl. Sawunggaling No. 7 \\
\hline 14. & Taeun Coffee & Jl. L.L R.E Martadinata No. 50 \\
\hline 15. & Noima Coffee & Jl. Mahmud No. 20 \\
\hline 16. & Righthands Coffee & Jl. Cisokan 8C \\
\hline 17. & Terminal Coffee & Jl. Hasanudin No. 3 \\
\hline 18. & Satu Pintu & Jl. Aceh No. 56 \\
\hline 19. & Ceritera & Jl. Gunung Kencana II No. 2 \\
\hline 20. & Kinokimi & Jl. Buah Batu No. 28 \\
\hline 21. & Greens And Beans & J1. Bahureksa No. 9 \\
\hline 22. & 2 Grams Coffee \& Meals & Jl. Ambon No. 16 \\
\hline 23. & Kahve & Jl. Ambon No. 14 \\
\hline 24. & Havana Coffee & Jl. Margacinta No. 1 \\
\hline
\end{tabular}

Sumber: Daftar Kedai Kopi Baru di Kota Bandung 2019

Menurut situs www.pergidulu.com, total sudah ada 85 kedai kopi baru yang ada di Kota Bandung. Grafik pertumbuhan kedai kopi di Kota Bandung dari tahun 2017 hingga 2019 dapat dilihat pada Gambar 2. 


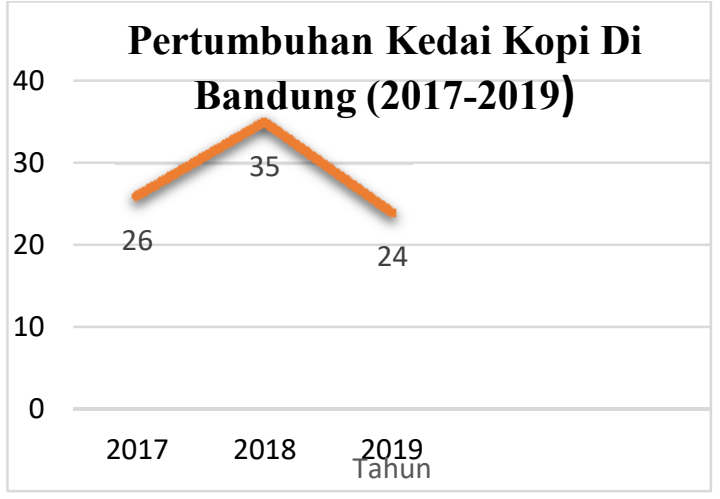

Gambar 2. Pertumbuhan Kedai Kopi Di Bandung (2017-2019)

Sumber: Adam dan Susan, 2019

Seiring dengan terus bertambahnya kedai kopi di Bandung membuat konsumen memiliki alternatif untuk memiliki kedai yang akan di kunjungi, artinya, tingkat persaingan antar kedai kopi semakin tinggi. Oleh karena itu, sangat penting bagi kedai kopi untuk menawarkan produk dan pelayanan yang sangat optimal dan mampu menarik konsumen dari ketatnya persaingan. Banyak kedai kopi yang menawarkan produknya, selain minuman kopi juga terdapat produk lain seperti makanan, kenyamanan tempat dan pelayanan. Dengan banyaknya penawaran produk dan pelayanan tersebut sangat mempengaruhi kepada tingkat kepuasan konsumen. Tingkat kepuasan konsumen sangat tergantung kepada selera dan karaktetistik konsumen itu sendiri. Jadi, kepuasan konsumen bukan hanya kepada core product, tetapi juga kenyamanan dan pelayanan.
Aditi Coffee House and Space merupakan salah satu kedai kopi yang menyajikan konsep kedai yang memperhatikan kenyamanan dan pelayanan terhadap konsumen. Aditi Coffee adalah kedai kopi yang memiliki konsep gaya minimal, namun rasa kopi yang maksimal. Meskipun lokasinya cukup jauh dari pusat kota, namun Aditi Coffee selalu ramai di datangi pengunjung. Aditi Coffee menggunakan desain minimalis modern, dipadukan dengan interior yang menyenangkan, serta terdapat banyak space yang dapat membuat konsumen lebih nyaman.

Kenyamanan dan pelayanan yang baik dari kedai kopi kopi Aditi ini diharapkan tercapainya kepuasan konsumen yang mengunjungi dan membeli produk di Aditi. Konsumen yang mengunjungi kedai kopi Aditi ratarata mencapai 100 orang per hari (Aditi Coffee House and Space, 2019). Namun menurut Supervisor Aditi Coffee, Ahdanisa (Kak Caca), besarnya rata-rata konsumen di Aditi Coffee belum menunjukan jumlah yang optimal jika mengacu pada consumer demographics (demografi konsumen). Aditi Coffee masih menemukan kesulitan untuk meraup target pasar yang sesuai dengan demografi/karakteristik konsumen yang 
telah ditetapkan. Berikut merupakan demografi konsumen yang telah di himpun oleh tim Aditi Coffee selama tahun 2019 dapat dilihat pada Tabel 4.

Maraknya kehadiran kedai kopi di Kota Bandung membuat persaingan tidak dapat dihindari. Persaingan membuat owner kedai kopi harus selalu melakukan research and development agar kedai kopi mereka tidak kalah bersaing dari segala sisi. Kepuasan konsumen adalah kunci karena experience atau pengalaman konsumen baru maupun konsumen tetap menjadi faktor yang sangat krusial untuk mempertahankan konsumen.

Jumlah rata-rata pengunjung Aditi Coffee cukup tinggi jika menilik kepada lokasi yang berada cukup jauh dari pusat kota atau pusat keramaian. Permasalahan di Aditi Coffee yaitu ingin mengetahui secara detail tentang kepuasan konsumen secara menyeluruh, apakah konsumen sudah merasa puas atau belum terhadap jasa dan pengelolaan yang dijalankan oleh kedai kopi Aditi Coffee, karena dengan adanya kepuasan konsumen yang berkunjung dan membeli produk di Aditi
Coffee maka diharapkan jumlah konsumen bertambah. Dengan menggunakan metode penelitian Customer Satisfaction Index (CSI), penulis berharap dapat membantu memecahkan permasalahan tersebut dan memperoleh informasi mengenai karakteristik konsumen dapat diketahui secara spesifik karena dilakukan dengan teknik wawancara.

Faktor yang sangat penting dan berpengaruh untuk kepuasan konsumen adalah kualitas bauran pemasaran yang ditawarkan oleh kedai kopi itu sendiri. Bauran pemasaran dapat membantu mengkaji sejauh mana produsen memberikan kepuasan terhadap konsumen dengan faktor-faktor yang sangat detail seperti produk (product), harga (prize), lokasi (place), dan sebagainya. Oleh sebab itu, dapat ditinjau dan dievaluasi poin mana saja yang harus ditingkatkan dan diperbaiki.

Berdasarkan fenomena diatas, maka penelitian analisis kepuasan konsumen pada pembelian produk di Aditi Coffee House and Space perlu dilakukan. 
Tabel 4. Demografi Konsumen oleh Tim Aditi Coffee tahun 2019

\begin{tabular}{|c|c|c|c|c|c|c|}
\hline \multicolumn{4}{|c|}{ Who } & \multirow{2}{*}{ When } & \multirow{2}{*}{ What } & \multirow{2}{*}{$\begin{array}{c}\text { How } \\
\text { Much/Person }\end{array}$} \\
\hline Ages & Come in & Gender & Purpose & & & \\
\hline \multirow{3}{*}{$18-25$} & \multirow{3}{*}{ Pair/groups } & $\begin{array}{l}\text { Male \& } \\
\text { female }\end{array}$ & Study & $10 \mathrm{am}-1 \mathrm{pm}$ & Coffee & 35.000 \\
\hline & & $\begin{array}{l}\text { Male \& } \\
\text { female }\end{array}$ & Hangout & $4 \mathrm{pm}-10 \mathrm{pm}$ & $\begin{array}{l}\text { Other drinks \& } \\
\text { nibbles }\end{array}$ & 50.000 \\
\hline & & Male & $\begin{array}{l}\text { Mobile } \\
\text { work }\end{array}$ & $1 \mathrm{pm}-6 \mathrm{pm}$ & Coffee \& meals & 50.000 \\
\hline \multirow{2}{*}{$26-35$} & \multirow{2}{*}{ Individual/pair } & Male & $\begin{array}{l}\text { Mobile } \\
\text { work/me } \\
\text { eting }\end{array}$ & $9 \mathrm{am}-10 \mathrm{pm}$ & Coffee \& meals & 60.000 \\
\hline & & $\begin{array}{l}\text { Male \& } \\
\text { female }\end{array}$ & Hangout & $5 \mathrm{pm}-10 \mathrm{pm}$ & $\begin{array}{l}\text { Coffee, other } \\
\text { drinks \& meals }\end{array}$ & 35.000 \\
\hline \multirow[t]{2}{*}{$35-45$} & \multirow[t]{2}{*}{ Groups } & Male & Meeting & $10 \mathrm{am}-2 \mathrm{pm}$ & $\begin{array}{l}\text { Coffee, nibbles } \\
\& \text { meals }\end{array}$ & 80.000 \\
\hline & & Male & Hangout & $1 \mathrm{pm}-8 \mathrm{pm}$ & Coffee & 60.000 \\
\hline
\end{tabular}

Sumber: Aditi Coffee House and Space, 2019

\section{METODE PENELITIAN}

Objek yang dikaji pada penelitian ini yaitu tingkat kepuasan konsumen Aditi Coffee. Tempat penelitian ditentukan berdasarkan pemilihan secara sengaja, dengan pertimbangan tempat tersebut berada di jauh dari pusat keramaian dan salah satu kedai kopi yang rata-rata jumlah konsumen per hari nya tinggi.

Desain penelitian menggunakan desain kualitatif. Menurut Gunawan (2013), penelitian kualitatif berusaha memahami dan menafsirkan makna suatu peristiwa interaksi tingkah laku manusia dalam situasi tertentu menurut perspektif peneliti sendiri. Untuk memenuhi data yang diperlukan, peneliti melakukan teknik wawancara ke lapangan langsung kepada informan dan konsumen. Menurut Subagyo (2011), wawancara adalah suatu kegiatan dilakukan untuk mendapatkan informasi secara langsung dengan mengungkapkan pertanyaan-pertanyaan pada para responden. Wawancara bermakna berhadapan langsung antara interviewer dengan informan, dan kegiatannya dilakukan secara lisan.

Teknik penelitian yang digunakan adalah studi kasus. Menurut Rahardjo (2017), Studi Kasus ialah suatu serangkaian kegiatan ilmiah yang dilakukan secara intensif, terinci dan mendalam tentang suatu program, peristiwa, dan aktivitas, baik pada tingkat perorangan, sekelompok orang, lembaga, 
atau organisasi untuk memperoleh pengetahuan mendalam tentang peristiwa tersebut.

Operasional variabel penelitian menurut Sugiyono (2014) adalah suatu atribut atau sifat atau nilai dari obyek atau kegiatan yang memiliki variasi tertentu yang telah ditetapkan oleh peneliti untuk dipelajari dan kemudian ditarik kesimpulannya. Kepuasan konsumen adalah tingkat perasaan konsumen setelah membandingkan antara apa yang konsumen dapatkan dan harapan konsumen (Umar, 2015). Operasionalisasi variabel yang digunakan dalam kuesioner mengacu kepada prinsip 7P bauran pemasaran, yaitu:

1. Product (Produk); produk berarti kombinasi barang dan jasa yang ditawarkan perusahaan kepada pasar sasaran.

2. Price (Harga); adalah nilai barang yang ditentukan atau dirupakan dengan uang.

3. Place (Tempat); organisasi yang saling menguntungkan dalam menjadikan suatu produk atau jasa untuk digunakan atau dikonsumsi.

4. Promotion (Promosi); semua kegiatan yang dilakukan perusahaan untuk mengkomunikasikan dan mempromosikan produknya kepada pasar sasaran.

5. Process (Proses); proses seleksi, pelatihan, dan pemotivasian karyawan yang nantinya dapat digunakan sebagai pembedaan perusahaan dalam memenuhi kepuasan pelanggan.

6. People (Orang); proses menjadi dua acara, yaitu: Complexity, dalam hal ini berhubungan dengan langkahlangkah dan tahap dalam proses. Divergernce, berhubungan dengan adanya perubahan dalam langkah tahap proses.

7. Physical Evidence (Bukti Fisik); bukti fisik adalah bukti yang dimiliki oleh penyedia jasa yang ditujukan kepada konsumen sebagai usulan nilai tambah konsumen. 
Tabel 5. Operasional Variabel

\begin{tabular}{|c|c|c|}
\hline Konsep & Variabel & Indikator \\
\hline \multirow[t]{22}{*}{ Kepuasan Konsumen } & Produk & Banyaknya variasi asal biji kopi yang tersedia \\
\hline & & Banyaknya variasi metode penyeduhan kopi \\
\hline & & Penampilan/penyajian minuman kopi \\
\hline & & Aroma dari minuman kopi \\
\hline & & Cita rasa pada minuman kopi \\
\hline & & Kebersihan produk kopi \\
\hline & Harga & Daya saing harga dengan produk serupa di tempat lain \\
\hline & & Keterjangkauan harga \\
\hline & & Kesesuaian harga dengan kualitas produk \\
\hline & Tempat & \multirow{6}{*}{$\begin{array}{l}\text { Akses lokasi yang mudah dijangkau } \\
\text { Suasana yang nyaman di area kedai } \\
\text { Jenis promosi di media sosial } \\
\text { Bentuk papan nama mudah ditemukan } \\
\text { Pelayan ramah dan sopan dalam melayani konsumen } \\
\text { Pelayan dapat memberikan informasi yang jelas mengenai } \\
\text { menu yang tersedia }\end{array}$} \\
\hline & & \\
\hline & Promosi & \\
\hline & & \\
\hline & Orang & \\
\hline & & \\
\hline & \multirow[t]{3}{*}{ Proses } & Proses pembuatan pesanan cepat \\
\hline & & Proses pembayaran mudah \\
\hline & & Pilihan metode pembayaran bervariasi \\
\hline & \multirow[t]{4}{*}{ Bukti Fisik } & Desain interior tempat \\
\hline & & Tersedianya fasilitas tambahan (wifi, buku, games kartu) \\
\hline & & Tersedianya tempat parkir yang aman \\
\hline & & Kebersihan tempat \\
\hline
\end{tabular}

\section{Customer Satisfaction Index (CSI)}

Tingkat kepuasan konsumen Aditi Coffee dianalisis dengan Customer Satisfaction Index (CSI). CSI berfungsi untuk menentukan tingkat kepuasan pelanggan secara menyeluruh dengan pendekatan yang mempertimbangkan tingkat kepentingan dari atrbut-atribut produk dan jasa yang diukur. Berikut adalah tahap-tahap metode pengukuran CSI:

1. Menentukan Mean Importance Score (MIS), tiap-tiap atribut

$M I S=\frac{\sum_{\mathrm{i}=1}^{\mathrm{n}} \mathrm{Y}_{\mathrm{i}}}{\mathrm{n}}$

Keterangan:

$\mathrm{n}=$ Jumlah responden

$\mathrm{Y}_{\mathrm{i}}=$ Nilai kepentingan variabel ke-i

$\mathrm{X}_{\mathrm{i}}=$ Nilai kinerja variabel ke-i
2. Membuat Weight Factors (WF) per atribut. Bobot ini merupakan presentase nilai MIS per variabel terhadap total MIS seluruh variabel.

$W F_{i}=\frac{\mathrm{MI} S_{i}}{\sum_{\mathrm{i}=1}^{\mathrm{p}} \mathrm{MIS}_{i}} \times 100 \%$

Keterangan:

$\mathrm{p}=$ Jumlah variabel kepentingan

$\mathrm{i}=$ Variabel ke- $\mathrm{i}$

3. Menentukan Mean Statisfaction Score (MSS) tiap atribut.

$M S S=\frac{\sum_{\mathrm{i}=1}^{\mathrm{n}} \mathrm{X}_{\mathrm{i}}}{\mathrm{n}}$

4. Membuat Weight Score (WSk) tiap atribut. Bobot ini merupakan perkalian.

$W S i=W F i \times M S S_{i}$

5. Menentukan Costumer Statisfaction Index (CSI) 
$C S I=\frac{\sum_{k=1}^{p} W S_{k}}{H S} \times 100 \%$

Keterangan: HS (Height Scale) $=$ skala maksimum yang digunakan.

Tabel 6. Tabel CSI (Customer Statisfaction Index)

\begin{tabular}{cc}
\hline Angka Indeks (\%) & Interpretasi \\
\hline $00-34$ & Tidak Puas \\
$35-50$ & Kurang Puas \\
$51-65$ & Cukup Puas \\
$66-80$ & Puas \\
$81-100$ & Sangat Puas \\
\hline
\end{tabular}

Sumber: Sumarwan, 2011

\section{Skala Likert}

Menurut Sugiyono (2014), skala likert digunakan untuk mengukur sikap, pendapat, dan persepsi seseorang atau sekelompok orang tentang fenomena sosial. Skala Likert memberikan pernyataan atau jawaban dengan gradasi mulai dari yang sangat positif hingga ke sangat negatif. Tabel 9. menjelaskan pemberian nilai pada Skala Likert.

Tabel 7. Nilai Skala Likert

\begin{tabular}{cl}
\hline Skor & \multicolumn{1}{c}{ Keterangan } \\
\hline 1. & Sangat Tidak Setuju (STS) \\
2. & Tidak Setuju (TS) \\
3. & Netral (N) \\
4. & Setuju (S) \\
5. & Sangat Setuju (SS) \\
\hline
\end{tabular}

Sumber: Sugiyono (2014)

\section{HASIL DAN PEMBAHASAN}

\section{Bauran Pemasaran Aditi Coffee}

Aditi Coffee sudah menggunakan konsep bauran pemasaran modern yang artinya sudah tidak hanya product, price, place, dan promotion, namun sudah ditambah dengan adanya people, physical evidence, dan process sehingga membuat
Aditi Coffee mempunyai bauran pemasaran yang luas.

\section{Karakteristik Konsumen menurut Jenis Kelamin}

Tabel 8. Karakteristik Konsumen Menurut Jenis Kelamin

\begin{tabular}{lcc}
\hline $\begin{array}{c}\text { Jenis } \\
\text { Kelamin }\end{array}$ & $\begin{array}{c}\text { Jumlah } \\
\text { Responden }\end{array}$ & Persentase \\
\hline Laki- Laki & 43 & $43 \%$ \\
Perempuan & 57 & $57 \%$ \\
\hline Total & $\mathbf{1 0 0}$ & $\mathbf{1 0 0 \%}$ \\
\hline
\end{tabular}

Berdasarkan data menurut Tabel 8 . dapat dilihat bahwa dari 100 responden, $43 \%$ konsumen adalah laki-laki, dan 57\% konsumen adalah perempuan. Hal ini menunjukkan bahwa perempuan mendominasi sebagai konsumen paling sering mengunjungi Aditi Coffee.

\section{Karakteristik Konsumen menurut Tempat Tinggal}

Tabel 9. Karakteristik Konsumen Menurut Daerah Tempat Tinggal

\begin{tabular}{lcc}
\hline $\begin{array}{c}\text { Daerah Tempat } \\
\text { Tinggal }\end{array}$ & $\begin{array}{c}\text { Jumlah } \\
\text { Responden }\end{array}$ & Persentase \\
\hline Kota Bandung & 88 & $88 \%$ \\
Kota Cimahi & 1 & $1 \%$ \\
Kab. Bandung & 11 & $11 \%$ \\
\hline \multicolumn{1}{c}{ Total } & $\mathbf{1 0 0}$ & $\mathbf{1 0 0 \%}$ \\
\hline
\end{tabular}

Berdasarkan data dari Tabel 9 . menunjukkan bahwa mayoritas responden bertempat tinggal di Kota Bandung dengan persentase $88 \%$. Sedangkan persentase responden yang berdomisili di luar Kota Bandung sebesar $12 \%$. Hal ini membuktikan bahwa Kota Bandung memiliki potensi dan peluang 
yang bagus bagi pebisnis yang ingin membuka kedai kopi.

\section{Karakteristik Konsumen menurut Usia}

Tabel 10. Karakteristik Konsumen Menurut Usia

\begin{tabular}{lcc}
\hline \multicolumn{1}{c}{ Usia } & $\begin{array}{c}\text { Jumlah } \\
\text { Responden }\end{array}$ & Persentase \\
\hline 16-21 Tahun & 12 & $12 \%$ \\
22-26 Tahun & 39 & $39 \%$ \\
27-31 tahun & 32 & $32 \%$ \\
$\geq 32$ Tahun & 17 & $17 \%$ \\
\hline Total & $\mathbf{1 0 0}$ & $\mathbf{1 0 0 \%}$ \\
\hline
\end{tabular}

Menurut data dari Tabel 10. usia responden dibagi menjadi beberapa bagian yaitu 16-21 tahun, 22-26 tahun, 27-31 tahun dan di atas 32 tahun. Dari total 100 responden, diperoleh hasil bahwa mayoritas konsumen Aditi Coffee berusia 22-26 tahun dengan persentase $39 \%$. Di posisi selanjutnya disusul oleh kelompok usia 27-31 tahun dengan persentase $32 \%$.

\section{Karakteristik Konsumen menurut Pendidikan Formal}

Tabel 11. Karakteristik Konsumen Menurut Pendidikan Formal

\begin{tabular}{ccc}
\hline $\begin{array}{c}\text { Lama } \\
\text { Pendidikan } \\
\text { Formal }\end{array}$ & $\begin{array}{c}\text { Jumlah } \\
\text { Responden }\end{array}$ & Persentase \\
\hline 12 Tahun & 15 & $15 \%$ \\
15 Tahun & 22 & $22 \%$ \\
16 Tahun & 60 & $60 \%$ \\
$>16$ Tahun & 3 & $3 \%$ \\
\hline Total & $\mathbf{1 0 0}$ & $\mathbf{1 0 0 \%}$ \\
\hline
\end{tabular}

Berdasarkan Tabel 11. diperoleh hasil bahwa karakteristik pendidikan terakhir konsumen Kedai Aditi Coffee didominasi oleh satu kelompok, yaitu responden yang memiliki pendidikan formal selama 16 tahun sebesar $60 \%$. Kelompok ini dapat dikatakan kelompok yang memiliki pendidikan terakhir S1.

\section{Karakteristik Konsumen menurut Pekerjaan}

Tabel 12. Karakteristik Konsumen Menurut Pekerjaan

\begin{tabular}{lcc}
\multicolumn{1}{c}{ Pekerjaan } & $\begin{array}{c}\text { Jumlah } \\
\text { Responden }\end{array}$ & Persentase \\
\hline Pelajar / mahasiswa & 28 & $28 \%$ \\
Ibu Rumah Tangga & 13 & $13 \%$ \\
Pegawai & 5 & $5 \%$ \\
Negeri/BUMN & 34 & $34 \%$ \\
Pegawai Swasta & 20 & $20 \%$ \\
Wiraswasta/Pengusaha & $\mathbf{1 0 0}$ & $\mathbf{1 0 0} \%$ \\
\hline \multicolumn{1}{c}{ Total } &
\end{tabular}

Berdasarkan Tabel 12. mayoritas konsumen Kedai Aditi Coffee adalah pegawai swasta dengan persentase sebesar $34 \%$. Disusul dengan pelajar/mahasiswa dengan persentase 28\%. Aditi Coffee adalah kedai kopi yang sangat nyaman untuk digunakan sebagai tempat bekerja atau rapat, maka tidak heran jenis pekerjaan konsumen yang mengunjungi kedai Aditi mayoritas pegawai swasta, pelajar/mahasiswa, dan wiraswasta/pengusaha. Hal yang unik pun terdapat di Aditi Coffee yang sangat akrab dengan kalangan ibu rumah tangga. Beberapa ibu rumah tangga mengatakan bahwa Aditi sangat cocok digunakan 
untuk tempat berkumpul bersama ibu rumah tangga lainnya untuk melakukan kegiatan seperti arisan atau hanya untuk bersantai saja.

\section{Karakteristik Konsumen menurut Pendapatan}

Tabel 13. Karakteristik Konsumen Menurut Pendapatan

\begin{tabular}{|c|c|c|}
\hline Pendapatan & $\begin{array}{c}\text { Jumlah } \\
\text { Responden }\end{array}$ & $\begin{array}{l}\text { Peatem pengusaha. } \\
\text { tase }\end{array}$ \\
\hline$<$ Rp.500.000 & 0 & Onalisis Tingkat Kepuasan Konsumen \\
\hline Rp. $500.000-$ Rp. 1.000 .000 & 8 & (Customer Satisfaction Index) \\
\hline Rp. $1.000 .001-$ Rp. 2.500 .000 & 18 & 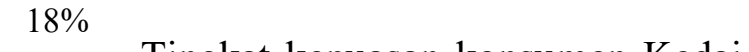 \\
\hline Rp. $2.500 .001-$ Rp. 5.000 .000 & 46 & Tingkat kepuasan konsumen Kedai \\
\hline$>$ Rp. 5.000 .000 & 28 & 28editi Coffee dihitung menggunakan \\
\hline Total & 100 & 10थ\% \\
\hline
\end{tabular}

Berdasarkan Tabel 13. karakteristik konsumen berdasarkan pendapatan per bulan di Kedai Aditi Coffee didominasi oleh konsumen dengan pendapatan per bulan Rp 2.500.000 - Rp 5.000.000 dengan persentase $46 \%$ disusul oleh konsumen dengan pendapatan per bulan lebih dari Rp5.000.000 dengan persentase $28 \%$. Jenis pekerjaan yang mendominasi pendapatan per bulan Rp 2.500.000 - Rp 5.000.000 yaitu pegawai swasta, dan pendapatan per bulan lebih dari Rp 5.000.000 didominasi oleh wiraswasta sebagaimana dapat dilihat pada Tabel 14 . Perhitungan hasil bagi nilai keseluruhan Weight Score dengan skala maksimum untuk penelitian ini adalah skala lima lalu dikalikan dengan 100\% sebagai berikut:

$$
\mathrm{CSI}=4,6625 / 5 \times 100 \%=93,25 \%
$$

Tabel 14. Tingkat Kepuasan Konsumen Berdasarkan Tingkat Kepentingan dan Tingkat Kinerja

\begin{tabular}{cllccc}
\hline & \multicolumn{1}{c}{ Atribut } & \multicolumn{2}{c}{ Tingkat Kepentingan } & \multicolumn{2}{c}{ Tingkat Kinerja } \\
\cline { 3 - 6 } No & \multicolumn{1}{c}{$\begin{array}{c}\text { Mean } \\
\text { Importance } \\
\text { Score }\end{array}$} & $\begin{array}{c}\text { Weight } \\
\text { Factors }\end{array}$ & $\begin{array}{c}\text { Mean } \\
\text { Performance } \\
\text { Score }\end{array}$ & $\begin{array}{c}\text { Weight } \\
\text { Score }\end{array}$ \\
\hline 1 & $\begin{array}{l}\text { Banyaknya variasi biji } \\
\text { kopi yang tersedia }\end{array}$ & 4.20 & 0.0402 & 4.46 & 0.1809 \\
2 & $\begin{array}{l}\text { Banyaknya variasi } \\
\text { metode penyeduhan kopi }\end{array}$ & 4.11 & 0.0394 & 4.40 & 0.1897 \\
3 & $\begin{array}{l}\text { Penampilan/penyajian } \\
\text { minuman kopi }\end{array}$ & 4.76 & 0,0456 & 4.77 & 0.1764 \\
4 & $\begin{array}{l}\text { Aroma dari minuman } \\
\text { kopi }\end{array}$ & 4.69 & 0.0449 & 4.72 & 0.1972 \\
5 & $\begin{array}{l}\text { Cita rasa pada minuman } \\
\text { kopi }\end{array}$ & 4.94 & 0.0473 & 4.71 & 0.2229 \\
6 & $\begin{array}{l}\text { Kebersihan produk kopi } \\
\text { Daya saing harga dengan } \\
\text { produk serupa di tempat }\end{array}$ & 4.90 & 0.0470 & 4.83 & 0.2227 \\
lain & 4.62 & 0.0443 & 4.57 & 0.1592
\end{tabular}




\begin{tabular}{|c|c|c|c|c|c|}
\hline \multirow[b]{2}{*}{ No } & \multirow[b]{2}{*}{ Atribut } & \multicolumn{2}{|c|}{ Tingkat Kepentingan } & \multicolumn{2}{|c|}{ Tingkat Kinerja } \\
\hline & & $\begin{array}{c}\text { Mean } \\
\text { Importance } \\
\text { Score }\end{array}$ & $\begin{array}{l}\text { Weight } \\
\text { Factors }\end{array}$ & $\begin{array}{c}\text { Mean } \\
\text { Performance } \\
\text { Score } \\
\end{array}$ & $\begin{array}{l}\text { Weight } \\
\text { Score }\end{array}$ \\
\hline 9 & $\begin{array}{l}\text { Kesesuaian harga dengan } \\
\text { kualitas produk }\end{array}$ & 4.88 & 0,0468 & 4.74 & 0.1795 \\
\hline 10 & $\begin{array}{l}\text { Akses lokasi yang mudah } \\
\text { dijangkau }\end{array}$ & 4.85 & 0,0465 & 4.73 & 0.1733 \\
\hline 11 & $\begin{array}{l}\text { Suasana yang nyaman di } \\
\text { sekitar kedai }\end{array}$ & 4.89 & 0.0469 & 4.68 & 0.2176 \\
\hline 12 & $\begin{array}{l}\text { Jenis promosi di media } \\
\text { sosial }\end{array}$ & 4.42 & 0.0424 & 4.29 & 0.2117 \\
\hline 13 & $\begin{array}{l}\text { Papan nama mudah } \\
\text { ditemukan }\end{array}$ & 4,72 & 0.0452 & 4.35 & 0.2230 \\
\hline 14 & Pelayan ramah dan sopan & 4.89 & 0.0469 & 4.81 & 0.2268 \\
\hline 15 & $\begin{array}{l}\text { Pelayan dapat } \\
\text { memberikan informasi } \\
\text { yang jelas mengenai } \\
\text { menu yang tersedia }\end{array}$ & 4.86 & 0.0466 & 4.76 & 0.2023 \\
\hline 16 & $\begin{array}{l}\text { Proses pembuatan } \\
\text { pesanan cepat }\end{array}$ & 4.78 & 0.0458 & 4.75 & 0.2157 \\
\hline 17 & $\begin{array}{l}\text { Proses pembayaran } \\
\text { mudah }\end{array}$ & 4.88 & 0.0468 & 4.62 & 0.2161 \\
\hline 18 & $\begin{array}{l}\text { Pilihan metode } \\
\text { pembayaran bervariasi }\end{array}$ & 4.74 & 0.0454 & 4.58 & 0.2080 \\
\hline 19 & Desain interior tempat & 4.74 & 0.0454 & 4.80 & 0.2180 \\
\hline 20 & $\begin{array}{l}\text { Tersedianya fasilitas } \\
\text { tambahan (wifi, buku, } \\
\text { permainan kartu) }\end{array}$ & 4.81 & 0.0461 & 4.72 & 0.2176 \\
\hline 21 & $\begin{array}{l}\text { Tersedianya tempat } \\
\text { parkir yang aman }\end{array}$ & 4.85 & 0.0465 & 4.71 & 0.2189 \\
\hline 22 & Kebersihan tempat & 4.99 & 0.0478 & 4.81 & 0.23 \\
\hline \multicolumn{5}{|c|}{ Total } & 4.6625 \\
\hline \multicolumn{5}{|c|}{ Customer Satisfaction Index (CSI) } & 93.25 \\
\hline
\end{tabular}

Berdasarkan data dari Tabel 14. hasil perhitungan menunjukkan bahwa nilai CSI Kedai Aditi Coffee House and Space adalah 93,25\% yang berada pada kategori sangat puas. Hal ini mengindikasikan bahwa sebagian besar konsumen Aditi Coffee merasa sangat puas terhadap atribut-atribut yang ada di Kedai Aditi Coffee. Meskipun nilai CSI menunjukan pada kategori sangat puas, terdapat $6,75 \%$ merasa belum puas. Artinya, Kedai Aditi Coffee perlu untuk terus meningkatkan kinerja pada setiap atribut bauran pemasaran $7 \mathrm{P}$ agar Kedai Aditi Coffee terus bersaing dan memberikan yang terbaik untuk konsumen.

\section{KESIMPULAN DAN SARAN}

\section{Kesimpulan}

Berdasarkan hasil penelitian yang telah dilakukan terhadap konsumen Kedai Aditi Coffee House and Space, kesimpulan yang dapat diambil dari penelitian ini antara lain 
1. Konsumen Kedai Aditi Coffee didominasi oleh perempuan, berdomisili di Kota Bandung, berusia 22-26 tahun, menempuh jenjang pendidikan selama 16 tahun atau $\mathrm{S} 1$, pekerjaan sebagai pegawai swasta disusul oleh pelajar/mahasiswa, dan berpendapatan rata-rata perbulan Rp2.500.000- Rp5.000.000.

2. Sebagian besar hasil penilaian konsumen yang mengacu kepada angka indeks kepuasan konsumen atau Customer Satisfaction Index (CSI), merasa sangat puas terhadap Kedai Aditi Coffee. Untuk mempertahankan dan meningkatkan kepuasan konsumen, Aditi Coffee perlu untuk terus memperbaiki dan meningkatkan kinerja pada setiap atribut kedai kopi.

\section{Saran}

Saran yang dapat menjadi bahan evaluasi atau perbaikan untuk kedai Aditi Coffee berdasarkan analisis CSI yaitu:

1. Aditi Coffee memiliki konsep kedai yang sangat baik, namun akan lebih sempurna apabila setiap karyawan atau barista menggunakan tanda pengenal. Misalnya seperti apron atau ID Card. Menurut pengalaman pribadi pada saat pertama kali mengunjungi
Aditi Coffee, penulis sempat kebingungan membedakan antara konsumen dan pegawai di Aditi Coffee.

2. Posisi bar dengan tempat mencuci gelas sebaiknya dipisah. Suasana kedai di Aditi Coffee sudah sangat nyaman. Mencampurkan kegiatan pesanan konsumen dengan tempat mencuci gelas sedikit mengurangi nilai keestetikan dan kehigienisan. Akan lebih baik apabila posisi tempat mencuci gelas sedikit disembunyikan atau bahkan dipindahkan ke tempat yang tidak terlihat oleh konsumen.

3. Aditi Coffee sudah memberikan fasilitas yang baik kepada konsumen, salah satunya tempat beribadah untuk konsumen yang beragama muslim. Namun, mushola di Aditi Coffee terbilang sangat kecil, hanya mampu digunakan oleh satu orang saja secara bergantian. Selain itu, mushola sebaiknya diberikan nuansa keislaman seperti karpet, sajadah, figura lafadz Allah dan Nabi Muhammad, atau gambar ka'bah.

4. Beberapa konsumen yang menyukai suasana outdoor di Aditi Coffee sering kali terganggu dengan banyaknya nyamuk. Aditi Coffee sudah memberikan lotion anti nyamuk 
untuk digunakan oleh konsumen. Namun, salah satu cara untuk mengurangi keberadaan nyamuk secara lebih alami yaitu menyimpan tanaman yang tidak disukai oleh nyamuk seperti serai wangi, lemon balm, lavender, catnip, dan geranium.

5. Untuk menarik konsumen lebih dalam, Aditi Coffee sebaiknya membuat promo-promo yang dapat menarik konsumen seperti misalnya diskon untuk yang sedang berulang tahun, diskon bagi konsumen yang datang dari jam 9 pagi sampai jam 11 siang, atau diskon di event-event tertentu. Promo tersebut dapat dijadikan konten di akun media sosial Aditi Coffee agar media sosial lebih hidup dan dapat menarik followers.

6. Aditi Coffee bisa memanfaatkan teknologi e-marketing seperti Facebook Ads atau Instagram Ads untuk lebih dikenal oleh konsumen khususnya di Kota Bandung. Mengacu kepada lokasi Aditi Coffee yang cukup jauh dari pusat kota atau pusat keramaian, Facebook Ads/Instagram Ads berfungsi sebagai media promosi brand atau tempat usaha dengan cara merekam segala aktivitas pengguna media sosial yang cocok dengan demografi konsumen
Aditi Coffee. Sehingga kontenkonten, lokasi, suasana kedai, dan lain sebagainya dapat muncul di lini masa media sosial pengguna Facebook atau Instagram.

7. Aditi Coffee sudah mempunyai papan nama, namun posisi papan nama tersebut terlalu menjorok kedalam sehingga tidak terlalu terlihat dan tercampur dengan papan nama perusahaan yang lain. Alangkah baiknya, Aditi Coffee memiliki papan nama secara terpisah dengan perusahaan lain agar terlihat lebih jelas bagi konsumen yang sedang mencari lokasi Aditi Coffee. Papan nama tersebut dapat di letakkan sedikit lebih menjorok ke luar.

\section{DAFTAR PUSTAKA}

Gunawan, I. (2013). Metode Penelitian Kualitatif. Bumi Aksara: Jakarta.

Hoffmann, J. (2014). The World Atlas of Coffee: From Beans to Brewing Coffees Explored, Explained and Enjoyed. North America: Firefly Books.

Rahardjo, M. (2017). Studi Kasus dalam Penelitian Kualitatif: Konsep dan Prosedurnya. Diakses pada 15 November 2019.

Sugiyono. (2014). Metode Penelitian Kuantitatif, Kualitatif, dan R\&D. Alfabeta: Bandung.

Susanti, A.A. dan Akbar. (2018). Outlook 2018 Komoditas Pertanian Subsesktor Perkebunan Kopi. Jakarta. Pusat Data dan Sistem 
ANALISIS KEPUASAN KONSUMEN PADA PEMBELIAN PRODUK DI ADITI COFFEE HOUSE AND

SPACE

Rizki Darmawan Karmana, Dini Rochdiani

Informasi Pertanian Sekretariat

Jenderal, Kementerian Pertanian

2018 